\title{
Atherosclerosis, Hypertension, and Diabetes in Alzheimer's Disease, Vascular dementia, and Mixed Dementia: Prevalence and Presentation
}

Keivan Javanshiri, Maria Landqvist Waldö, Niklas Friberg, Fredrik Sjövall, Karin Wickerström, Mattias Haglund and Elisabet Englund

[Journal of Alzheimer's Disease, 65(4)2018, 1247-1258, DOI 10.3233/JAD-180644]

https://content.iospress.com/articles/journal-of-alzheimers-disease/jad180644

On page 1253, the right column, line 6 from the bottom, the text gives [58] as a reference:

"In 2013, the prevalence of DM was reported to be $15.6 \%$ among the normal Swedish population in individuals $>65$ years [58], which is an age group in proximity to our study group (81 years, SD 9)."

However, in the References section, reference [58], Bucht et al, is not the correct reference for this text. The correct reference is:

Andersson T, Ahlbom A, Carlsson S. Diabetes Prevalence in Sweden at Present and Projections for Year 2050. PLoS ONE. 2015;10(11):e0143084. 